\title{
Avaliação da eliminação de bioaerossóis em filtros de malha modificados com nanopartículas de prata
}

\author{
Elimination of evaluation of bioaerosols \\ in mesh filter modified with silver nanoparticles
}

Paula de Freitas Rosa', Mônica Lopes Aguiar², André Bernardo³

\begin{abstract}
RESUMO
O monitoramento da qualidade do ar interior (QAI) vem ganhando cada vez mais atenção nas pesquisas atuais, no entanto existem poucos trabalhos relacionados ao desenvolvimento de técnicas para minimizar os efeitos da poluição do ar interior. O objetivo deste estudo foi modificar os tecidos de malha poliéster e viscose (PV) com nanopartículas de prata, a fim de usá-los em aparelhos de ar-condicionado. Para alcançar esse objetivo, tecidos foram modificados por imersão dos filtros nas suspensões de nanopartículas. Depois da secagem do filtro, a coleta de material particulado foi feita em um banheiro de uma instituição de ensino superior. Os resultados mostraram que os filtros impregnados com nanopartículas de prata foram capazes de reduzir significativamente a atividade de microrganismos presentes no material
\end{abstract} particulado no ar, encontrando valores entre 22 e $83 \%$.

Palavras-chave: nanopartículas; prata; filtração.

\section{ABSTRACT}

The monitoring of indoor air quality $(\mathrm{IQQ})$ is gaining increasing attention on current research. However, there has been less work concerning the development of techniques to mitigate the effects of indoor air pollution. The aim of this study was to modify polyester-viscose (PV) mesh fabrics with silver nanoparticles, in order to use them in air conditioners. To reach this objective, common fabrics purchased from commercial sources were modified by immersion of the chosen filters in nanoparticle suspensions. After drying the filter, collection of particulate matter was made in a higher education institution. The results showed that the filters impregnated with silver nanoparticles were able to significantly reduce the activity of microorganisms present in the airborne particulate matter. by between 22 and $83 \%$.

Keywords: nanoparticles; silver; filtration.

\section{INTRODUÇÃO}

O aumento da expectativa de vida dos seres humanos tem levado a sociedade à maior preocupação com problemas relacionados à qualidade de vida. Assim como a boa alimentação e a prática de exercícios, itens já consolidados na busca do bem-estar pessoal, pode-se considerar a qualidade do ar que se respira todos os dias fator igualmente necessário.

Dessa forma, o monitoramento da qualidade do ar é algo de extrema relevância para a saúde humana. É sabido por todos que, com o avanço tecnológico e, por conseguinte, com o desenvolvimento industrial, a qualidade do ar que respiramos tem gradualmente diminuído. Logo, é importante que haja o desenvolvimento de novas metodologias para reparar os danos causados por esses avanços.

Uma variável bastante interventora na qualidade do ar interno (QAI) é a concentração de microrganismos em suspensão no ar, cuja classe é denominada de bioaerossóis. Esses contaminantes podem ser os causadores dos principais problemas de alguns ambientes fechados, como prédios e escritórios, por serem, possivelmente, os causadores número 1 de alergias e doenças infecciosas. Por esse motivo, este trabalho propôs uma metodologia para a minimização de bioaerossóis (bactérias e fungos) presentes no ar de ambientes internos por meio da utilização de nanopartículas de prata (AgNP) impregnadas em filtros, de maneira especial para os ambientes chamados de "salas limpas", onde é necessário mais controle acerca dos poluentes existentes em seu interior.

As AgNP foram escolhidas por apresentarem potencial poder biocida, sendo esse efeito relacionado à inativação das enzimas pela prata. Logo, a principal motivação para a realização deste trabalho foi a pequena quantidade de estudos na área de filtração sólido-gás que faça o uso de filtros impregnados com nanopartículas.

\section{METODOLOGIA}

\section{Meios filtrantes}

O meio filtrante utilizado foi adquirido em comércio convencional. Foi escolhido o tecido de malha poliéster e viscose (PV), por ser comum em todos os estabelecimentos pesquisados. Outro meio filtrante empregado 
foi o de celulose High-Efficiency Particulate Air (HEPA), fornecido pela empresa Veco do Brasil Indústria e Comércio de Equipamentos Ltda. Esse meio filtrante era disposto logo abaixo dos filtros sem modificação ("branco") e impregnado com o intuito de ser o controle.

\section{Teste de permeabilidade dos meios filtrantes}

A análise da perda de carga foi feita por meio do uso de um sistema composto de um manômetro, um compressor, um rotâmetro e uma bomba a vácuo. Com auxílio do rotâmetro, variou-se a vazão de fluido que atravessava o meio filtrante. A cada variação efetuada, um valor para a queda de pressão era anotado para posterior cálculo de permeabilidade. Na Figura 1 é apresentado o equipamento descrito, em que:

1. bomba a vácuo;

2. rotâmetro

3. suporte dos filtros

4. manômetro, no qual são registradas as pressões.

\section{Testes de eficiência}

Na Figura 2 é ilustrado um esquema do equipamento utilizado, o qual era composto por uma unidade controladora de pressão (1), um alimentador de partículas (2), um suporte do meio filtrante (3), uma bomba a vácuo (4), um rotâmetro (5), um contador de partículas (6) e um computador (7). Nesse equipamento, após o ajuste da pressão, o material particulado era alimentado e, por intermédio da sucção realizada pela bomba e controlada pelo rotâmetro, depositava-se o material no meio filtrante.

Para o cálculo da eficiência de coleta foram avaliadas as quantidades de partículas na entrada e na saída do suporte do meio filtrante, ou seja, antes e após a passagem pelo meio filtrante, sendo contabilizadas com o auxílio do contador de partículas (APS). Os dados foram armazenados no computador para posterior cálculo.

\section{Local de coleta}

O banheiro feminino do Departamento de Engenharia Química (DEQ) da Universidade Federal de São Carlos (UFSCar) foi escolhido como o local de coleta, por conta do grande número de pessoas que transitam por ele. O tempo de amostragem foi de uma hora, e a vazão escolhida para os testes, de $60 \mathrm{~L} \cdot \mathrm{h}^{-1}$. Essa vazão de ar foi selecionada com o objetivo de simular a vazão da respiração de um homem em repouso.

\section{Coleta do bioaerossol}

Os bioaerossóis foram coletados por meio de um sistema de filtração desenvolvido por Catranis et al. (2006). O sistema é composto por dois funis com garra, marca Nalgene, modelo 315-0047; três medidores de vazão tipo rotâmetro marca ASA, escala de 400 a $1.600 \mathrm{~L} / \mathrm{min}$, e uma bomba de vácuo da marca Fisatom, modelo 820, conforme observado na Figura 3. O funil com a garra é fixado em uma haste cuja altura em relação ao solo é ajustável. Nesta pesquisa, foi utilizada a altura de 1,45 m.

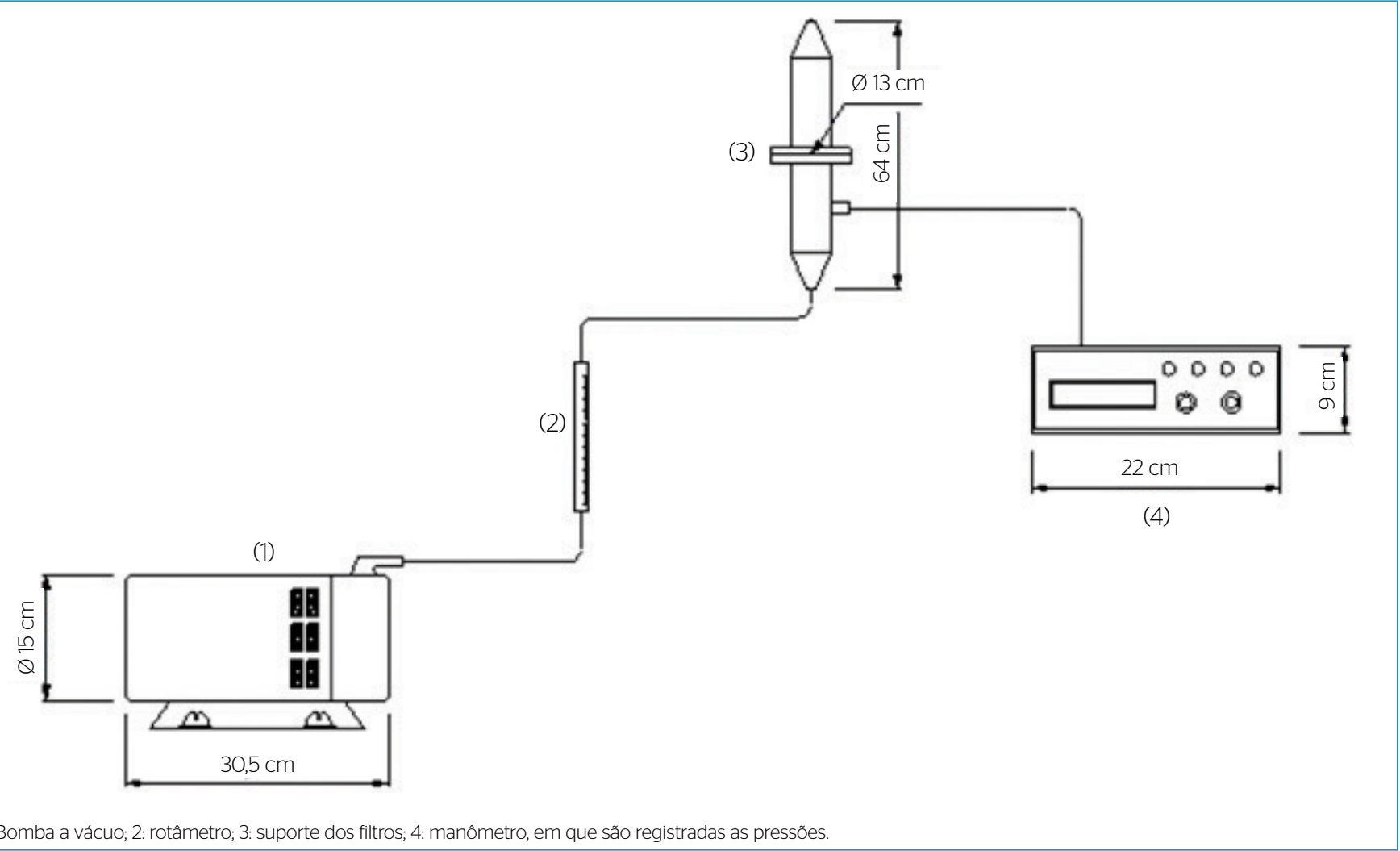

Figura 1 - Sistema empregado para avaliação da perda de carga nos filtros testados. 
O equipamento demonstrado na Figura 3 foi montado de modo a permitir dois níveis de coleta de material particulado do ar. No primeiro nível, localizado no bocal dos funis, ocorria a filtração pelo tecido de malha PV dos testes. No segundo nível, na saída dos funis, filtros HEPA retinham todo o material particulado que eventualmente não fora retido na malha PV. Os dois funis eram utilizados simultaneamente de modo a submeter ao teste ao mesmo tempo um filtro impregnado com AgNP e outro não impregnado ("branco").

\section{Preparo das nanopartículas de prata}

As dispersões coloidais de prata foram preparadas por intermédio do método de síntese originalmente proposto por Turkevich et al. (1951), o qual também é conhecido como método do citrato. Utilizaram-se para tal o sal de nitrato de prata e o citrato de sódio como agente redutor.

\section{Técnicas de análise das nanopartículas}

Para as análises das nanopartículas foram utilizados os equipamentos microscópio de varredura FEI Inspect S50, pertencente ao Laboratório de Caracterização Estrutural do Departamento de Engenharia de Materiais (DEMa) da UFSCar, o microscópio eletrônico de transmissão modelo FEI Tecnai G² F20 HRTEM, do mesmo laboratório, e um espectrofotômetro de absorção ultravioleta visível (UV-vis) modelo Ultrospec 2000, do Laboratório de Catálise do DEQ/UFSCar.

\section{Impregnação dos filtros}

A impregnação do filtro foi realizada mediante a imersão dos filtros em béqueres contendo as suspensões de nanopartículas de prata. O volume de suspensão utilizado foi de $250 \mathrm{~mL}$. Essa imersão foi feita sem agitação, pois a superfície do filtro se encontrava totalmente em contato com a suspensão, e o tempo de imersão foi de 24 horas. A secagem desses filtros aconteceu em estufa a $60^{\circ} \mathrm{C}$ até o dia de uso.

\section{Preparo dos meios de cultura e das placas de Petri e contagem dos microrganismos}

O meio de cultura do tipo Agar Nutriente da série Mikrobiologie foi empregado para a cultura de bactérias e fungos, e efetuou-se seu preparo de acordo com as recomendações indicadas no rótulo. O material particulado retido nos filtros foi plaqueado e posteriormente analisado.

Após serem realizados testes preliminares, notou-se o aparecimento nas placas de microrganismos impossíveis de serem contabilizados em unidades formadoras de colônia (UFCs), uma vez que se viu a presença de microrganismos filamentosos, impossibilitando assim a contagem deles por essa técnica. Portanto, julgou-se necessário adotar outra metodologia de contagem. A metodologia escolhida para avaliar quantitativamente o teor de microrganismos foi a de massa seca. O cálculo da massa seca foi realizado por meio da subtração da massa do tubo da massa do tubo contendo as células.

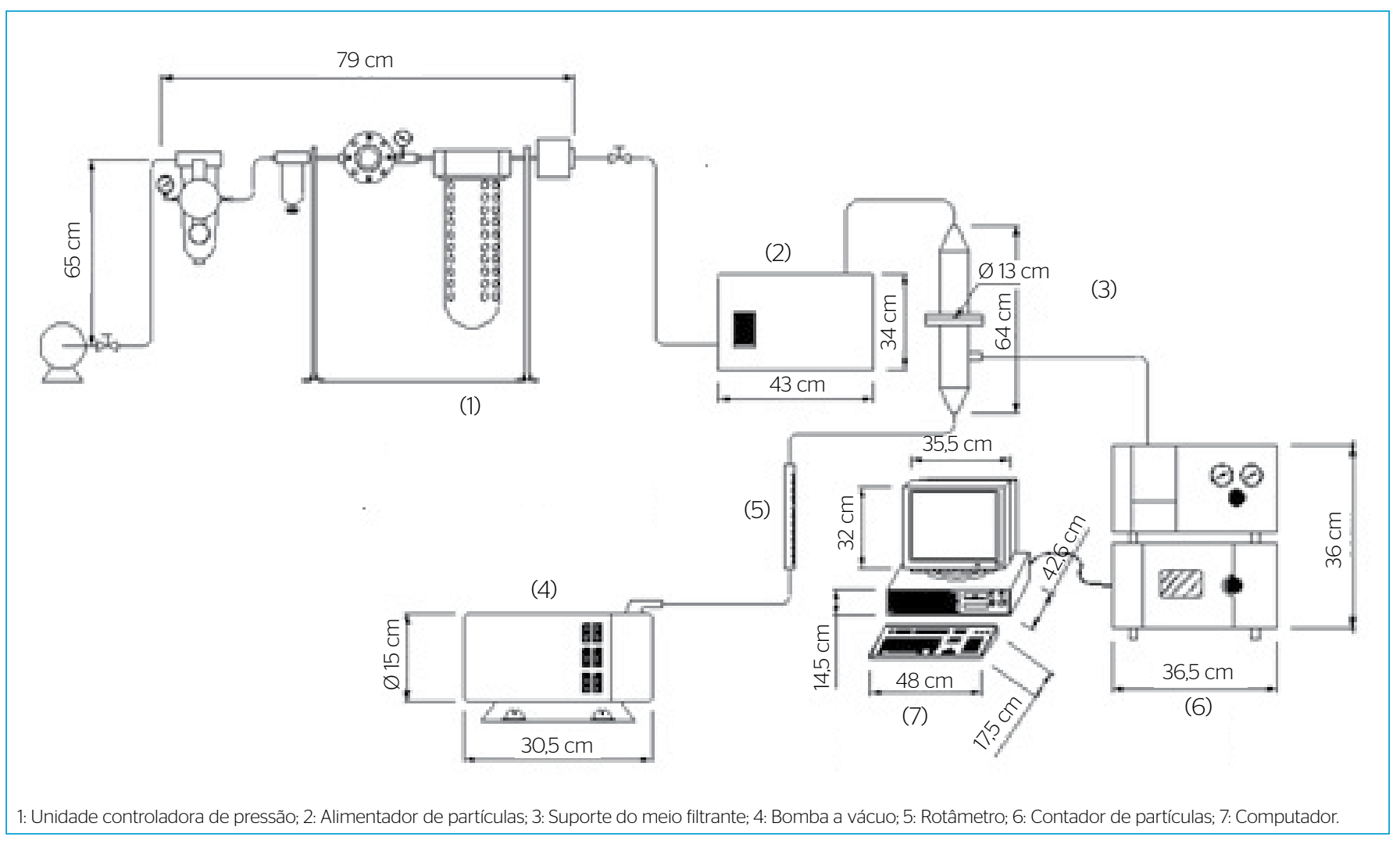

Figura 2 - Equipamento utilizado para medidas de eficiência de coleta. 


\section{RESULTADOS E DISCUSSÃO}

Permeabilidade dos tecidos comerciais impregnados com nanopartículas de prata

A permeabilidade Darciana foi calculada utilizando a equação de Darcy. Considerando os dados experimentais e realizando os cálculos, viu-se que a permeabilidade Darciana para o tecido malha PV impregnado com nanopartículas era de $\mathrm{k}_{1}=1,1 \times 10^{-10} \mathrm{~m}^{2}$.

A Figura 4 apresenta os dados de eficiência média de coleta $\times$ diâmetro aerodinâmico, realizado com pó de rocha fosfática com tamanho médio de partículas de $1,5 \mathrm{~mm}$. O equipamento utilizado proporciona varredura de tamanho menor do que 0,523 até $19,81 \mathrm{~mm}$, porém na

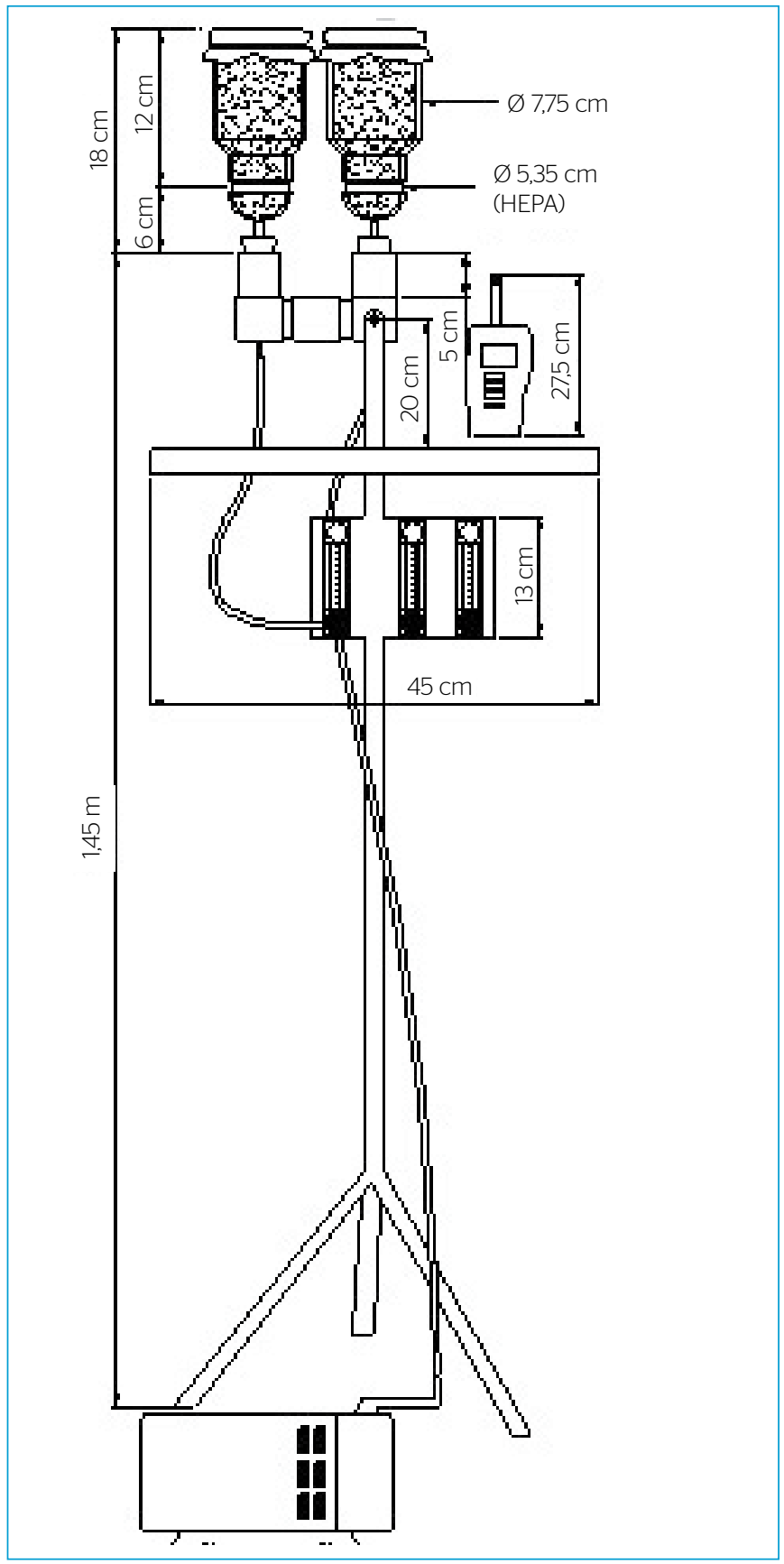

Figura 3 - Equipamento utilizado para coleta do material particulado. faixa acima de 6,732 mm não se encontram partículas. Ao analisar a figura supracitada, é notável que a eficiência média de coleta possui valores acima de $90 \%$ para a todos dos diâmetros estudados.

\section{Análise da suspensão de nanopartículas de prata por meio do método de espectrofotometria ultravioleta visível}

Para verificar se a suspensão sintetizada de fato correspondia a nanopartículas de prata, foram feitas algumas medidas de comprimento de onda, e verificou-se que as nanopartículas sintetizadas absorveram no comprimento de onda esperado (SOLOMON et al., 2007). Segundo Solomon et al. (2007), o comprimento de onda é dependente do tamanho das nanopartículas formadas e pode variar de 380 a $450 \mathrm{~nm}$.

Analisando o gráfico ilustrado na Figura 5, nota-se que os comprimentos de onda com máxima absorbância é entre 415 e 440 . Dessa forma, levando em conta a distribuição de Solomon et al. (2007), conclui-se que as nanopartículas possuem tamanhos variáveis entre 35 e aproximadamente $60 \mathrm{~nm}$.

\section{Análise da suspensão de nanopartículas de prata mediante o método de microscopia eletrônica de transmissão}

A Figura 6 apresenta a imagem de microscopia eletrônica de transmissão das AgNP.

Ao analisar tal figura, é possível confirmar que de fato o material sintetizado se encontrava na faixa nanométrica, com tamanho médio de cerca de $50 \mathrm{~nm}$.

\section{Distribuição granulométrica de nanopartículas de prata utilizando equipamento de filtração acoplado a um contador scanning mobility particle sizer}

Na Figura 7 está ilustrada a distribuição granulométrica das nanopartículas sintetizadas por intermédio do método de Turkevich. Esse teste foi realizado utilizando um equipamento de filtração acoplado a um detector de partículas scanning mobility particle sizer (SMPS).

Com base na análise da Figura 7, nota-se que as partículas se encontram majoritariamente próximo a $50 \mathrm{~nm}$, o que reforça que o método empregado para síntese de nanopartículas é eficaz para a obtenção de partículas até $100 \mathrm{~nm}$.

$\mathrm{Na}$ Tabela 1 são apresentados os teores de eliminação de microrganismos obtidos para os três testes efetuados.

Os cálculos desses testes foram feitos levando-se em conta o teor de massa seca obtido nos filtros "brancos" comparado ao teor encontrado nos filtros impregnados.

A Tabela 1 apresenta dois tipos de resultados: a redução de microrganismos no filtro de malha PV impregnado com AgNP exposto a bioaerossol em relação a um "branco" $(39,19 \pm 7,64 \%)$, e a redução de microrganismos provenientes da passagem de bioaerossol pelo 
filtro de malha PV impregnado com AgNP em relação a um "branco" $(60,31 \pm 32,76 \%)$. Os resultados foram bastante distintos entre si tanto quanto no tocante ao valor médio quanto ao desvio padrão das médias. Os resultados de redução de microrganismos no ar que passa pelo filtro impregnado com AgNP foram muito distintos dos outros dois $(75,62 ; 82,62 ; 22,70 \%)$. Se esse resultado for desconsiderado, a redução de microrganismos do ar através de um filtro de malha PV impregnado com AgNP passa a ser 79,12 $\pm 4,95 \%$.
Aparentemente, os filtros impregnados com AgNP reduzem a concentração de microrganismos do ar pela retenção física do bioaerossol (o filtro de malha mostrou-se capaz de reter $90 \%$ de todas as partículas menores de $6,732 \mu \mathrm{m}$ ) e pela inviabilização dos microrganismos pela ação biocida das AgNP (a redução média de 39,19\% dos microrganismos retidos no filtro impregnado com AgNP). As análises de reúso dos filtros serão realizadas no projeto de doutorado da autora. Este trabalho fez parte do seu projeto de mestrado.

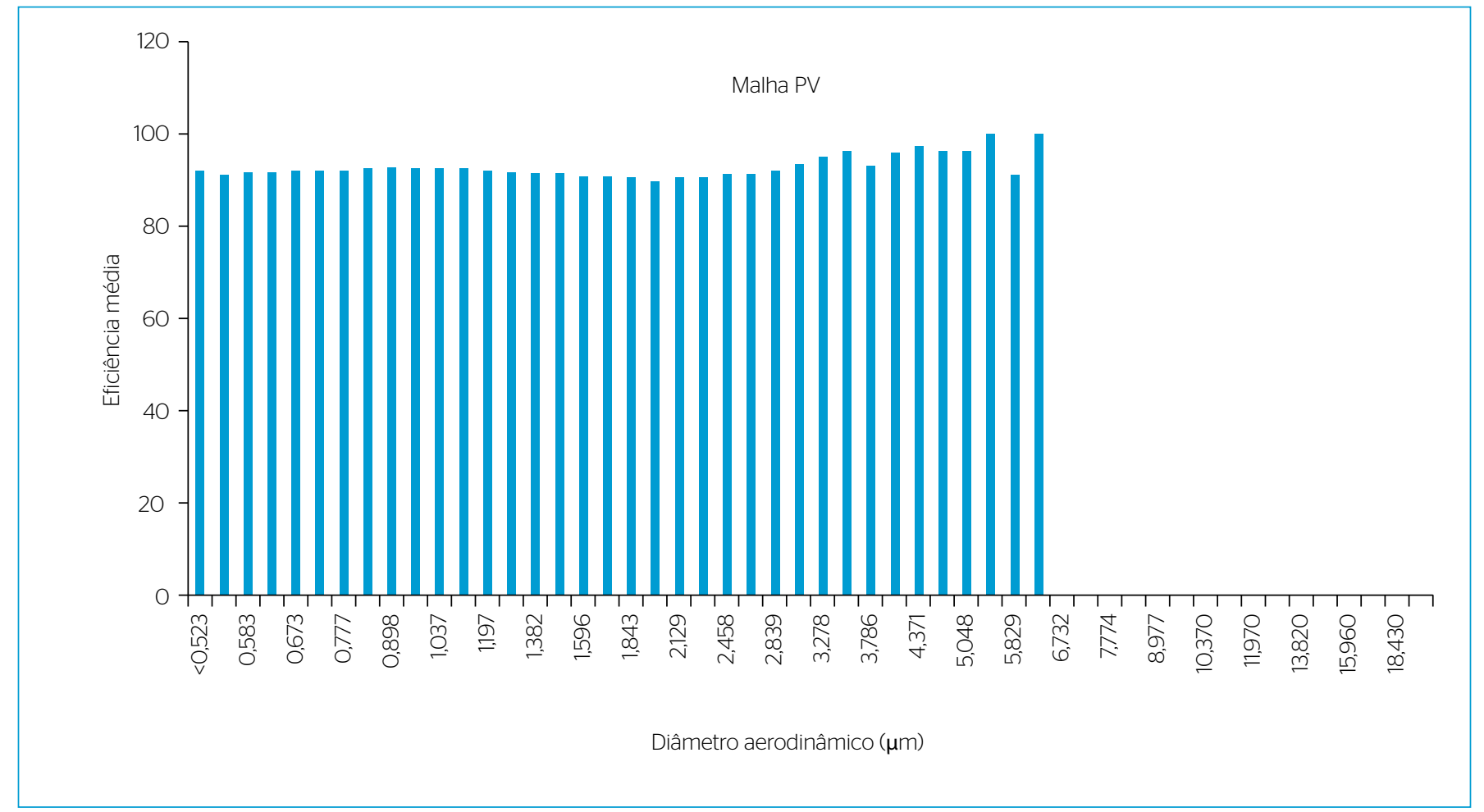

Figura 4 - Eficiência de coleta do tecido malha PV.

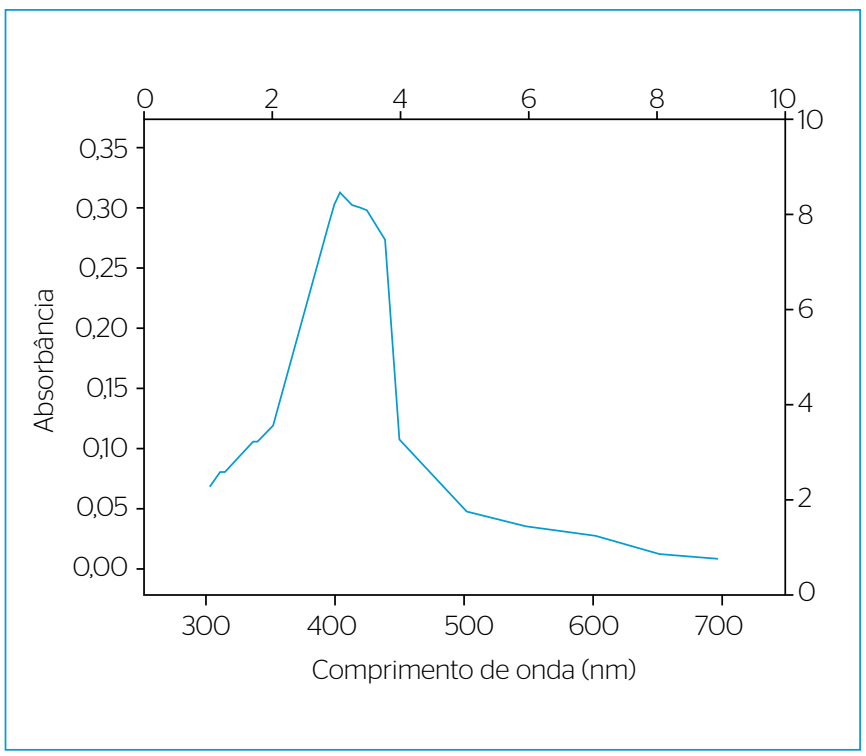

Figura 5 - Distribuição da absorbância versus comprimento de onda da suspensão de nanopartículas de prata.

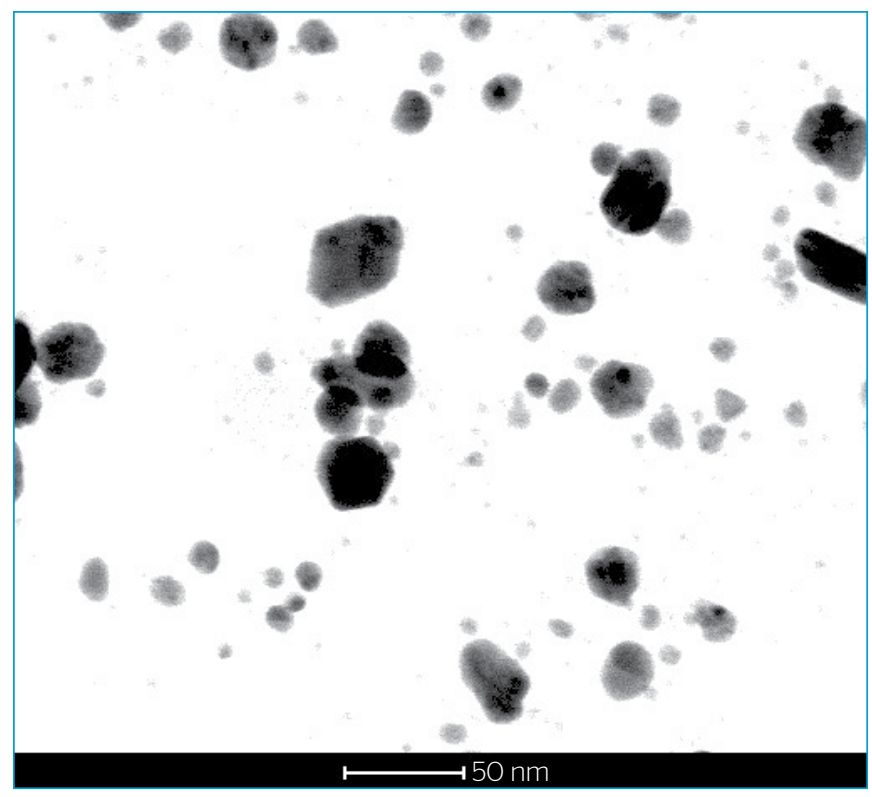

Figura 6 - Nanopartículas de prata. 


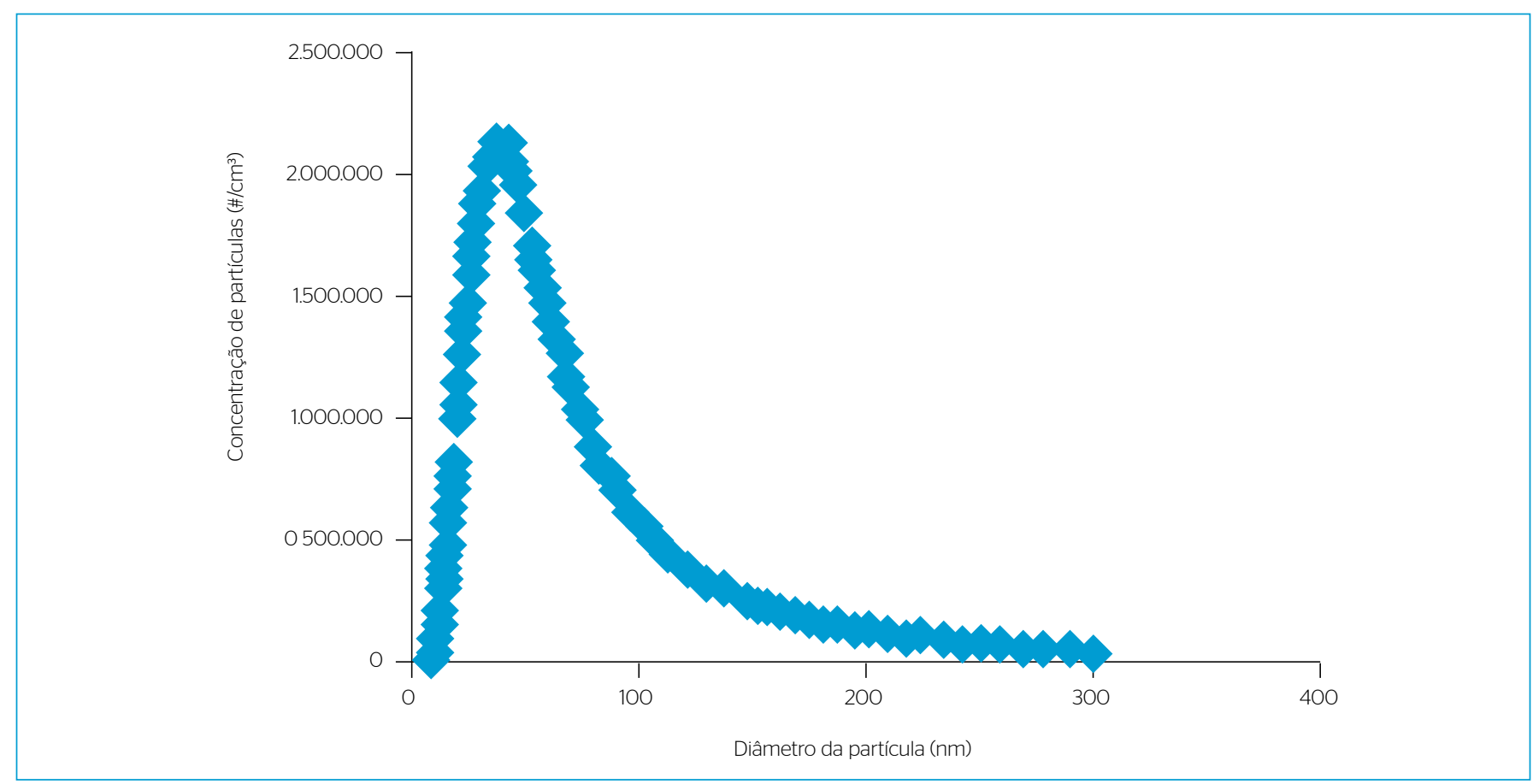

Figura 7 - Distribuição granulométrica das nanopartículas de prata.

Tabela 1 - Valores de porcentagem de redução de microrganismos para os três testes efetuados.

\begin{tabular}{|c|c|c|c|c|c|}
\hline \multicolumn{6}{|l|}{ Malha PV } \\
\hline \multicolumn{2}{|l|}{ Ensaio 1} & \multicolumn{2}{|c|}{ Ensaio 2} & \multicolumn{2}{|c|}{ Ensaio 3} \\
\hline $\begin{array}{l}\text { Filtro "branco" × } \\
\text { filtro impregnado }\end{array}$ & $\begin{array}{l}\text { HEPA "branco" × } \\
\text { HEPA impregnado }\end{array}$ & $\begin{array}{l}\text { Filtro "branco" } \times \\
\text { filtro impregnado }\end{array}$ & $\begin{array}{l}\text { HEPA "branco" } \times \\
\text { HEPA impregnado }\end{array}$ & $\begin{array}{l}\text { Filtro "branco" x } \\
\text { filtro impregnado }\end{array}$ & $\begin{array}{l}\text { HEPA "branco" } \times \\
\text { HEPA impregnado }\end{array}$ \\
\hline $46,32 \%$ & $75,62 \%$ & $31,13 \%$ & $82,62 \%$ & $40,13 \%$ & $22,70 \%$ \\
\hline
\end{tabular}

\section{CONCLUSÃO}

Com base nos resultados obtidos, concluiu-se que o meio filtrante de malha PV foi efetivamente impregnado com AgNP por intermédio da imersão do tecido em suspensão. Além disso, verificou-se que o meio filtrante impregnado com AgNP mantém suas características, como permeabilidade e eficiência de coleta, praticamente inalteradas. A impregnação com AgNP deu ao meio filtrante características biocidas, comprovadas pela diminuição da população de microrganismos no ar passante, que, no melhor caso, chegou a $82 \%$ em relação ao filtro não impregnado.

Este estudo também indicou a importância do desenvolvimento de tecnologias que visam à melhoria da qualidade do ar. Cabe ressaltar que não podemos ver como está a qualidade do ar que respiramos, mas, mediante pesquisas como esta, é possível saber que ele está danificado, podendo levar as instituições e órgãos governamentais a tomarem medidas com o intuito de repará-lo.

\section{REFERÊNCIAS}

CATRANIS, C.M.; ANAGNOST,S.E.;ZHANG, L.; ZHOU, S.; FERNANDO, A.; MOREY, S.; WANG, C.J.K. (2006) A new sub-sampling method for analysis of air samples collected with the Andersen singlestage sampler. Aerobiologia, v. 22, p. 177-184.

SOLOMON, S.D.; BAHADORY, M.; JEYARAJASINGAN, A.V.; RUTKOWSKY, S.A.; BORITZ, C.; MULFINGER, L. (2007) Synthesis of silver nanoparticles. Journal of Chemical Education, v. 84, n. 2, p. 322-325.

TURKEVICH, J.; STEVENSON, P.C.; HILLIER, J. (1951) A study of the nucleation and growth processes in the synthesis of colloidal gold. Discussions of the Faraday Society, v. 11, p. 55-75. 